\title{
E1A is sufficient by itself to induce apoptosis independent of p53 and other adenoviral gene products
}

\author{
BM Pützer*,1,2, T Stiewe ${ }^{1,2}$, K Parssanedjad ${ }^{1}$, S Rega $^{1}$ and \\ H Esche ${ }^{1}$ \\ 1 Institute of Molecular Biology (Cancer Research), University of Essen, Medical \\ School, Hufelandstr. 55, 45122 Essen, Germany \\ 2 Both authors contributed equally to the data presented in this article \\ * Corresponding author: Institute of Molecular Biology (Cancer Research), \\ University of Essen, Medical School, Hufelandstr. 55, 45122 Essen, Germany. \\ Tel: 49201723 3153; Fax: 49201723 5974; \\ E-mail: brigitte.puetzer@uni-essen.de
}

Received 23.8.99; revised 4.10.99; accepted 18.10.99 Edited by M Oren

\begin{abstract}
Induction of apoptosis seems to be a key function in maintaining normal cell growth by exerting negative controls on cell proliferation and suppressing tumorigenesis. The adenovirus E1A oncogene shows both cell cycle progression and apoptotic functions. To understand the mechanism of E1A-induced apoptosis, the apoptotic function of E1A 13S was investigated in p53-null cells. We show here that E1A is sufficient by itself to induce substantial apoptosis independent of $p 53$ and other adenoviral genes. The apoptotic function of E1A is accompanied by processing of caspase-3 and cleavage of poly(ADP-ribose)-polymerase. Cell death is significantly blocked by the caspase inhibitor ZVAD-fmk and when coexpressed with $\mathrm{E} 1 \mathrm{~B} 19 \mathrm{~K}, \mathrm{Bcl}-2$ or the retinoblastoma protein (RB). Analyses of E1A mutants indicated that the apoptotic activity of E1A correlates closely with the ability to bind the key regulators of E2F1-induced apoptosis, p300 and RB. Finally, in vivo relevance of down-modulation of p53independent apoptosis for efficient transformation is demonstrated. Cell Death and Differentiation (2000) 7, 177-188.
\end{abstract}

Keywords: E1A; apoptosis; RB; p300; transformation

\section{Introduction}

Apoptosis plays an important role in sustaining normal tissue homeostasis by balancing the effects of proliferation. The process of apoptosis is controlled through the expression of a large number of genes, many of which are conserved from nematodes to mammals and viruses. ${ }^{1}$ Disruption of this process is believed to result in uncontrolled cell growth, which may contribute to tumorigenesis and neoplastic progression. ${ }^{2}$

Several of the best understood tumor suppressor proteins such as the retinoblastoma protein (RB) and p53, whose function is frequently lost in many human cancers, have a key function in transducing a variety of growth inhibitory signals to the cell cycle control machinery. ${ }^{3}$ One indication of the pivotal roles played by these regulatory products is the observation that they are each targeted by the adenovirus $\mathrm{E} 1 \mathrm{~A}$ and $\mathrm{E} 1 \mathrm{~B}$ genes, respectively. ${ }^{4} \mathrm{By}$ interaction with cellular proteins, E1A pushes cells through their cell cycle, thereby facilitating virus reproduction. Probing cell growth control mechanisms with virus gene products manipulated in vitro has helped to elucidate how the biological functions and interactions of RB and p53 connect with the pathways of transcription control, transformation and apoptosis. E1A studies have contributed to our current understanding that RB, one member of the pocket protein family, together with associated cyclins and cyclin-dependent kinases can modulate the activity of the cellular transcription factor $\mathrm{E} 2 \mathrm{~F} 1,{ }^{5}$ which exerts dual functions as a positive regulator of both cell proliferation and apoptosis. ${ }^{6}$

The RB protein silences specific genes that are active in Sphase of the cell cycle and which are regulated by members of the E2F family ${ }^{7}$ by direct binding to E2F. ${ }^{8} \mathrm{RB}$, which is recruited to target promoters by $\mathrm{E} 2 \mathrm{~F}$, represses transcription likely by masking the E2F transactivation domain ${ }^{9}$ and by recruiting a histone deacetylase, HDAC1, via the RB pocket domain. ${ }^{10,11}$ HDAC1 physically interacts and cooperates with $\mathrm{RB}$, thereby modulating the local chromatin structure. The HDAC1-motif involved in RB interaction shows similarity to that used by viral oncoproteins. ${ }^{11}$ In the currently accepted model, E1A binds and inactivates RB by competing with HDAC1 for RB interaction, ${ }^{12}$ which in turn leads to the release of E2F and activation of E2F target genes. Finally, E1A may accomplish E2F release in a two-step process: upon binding the RB protein via conserved region 2 (CR2), it displaces RB from E2F via conserved region 1 (CR1). ${ }^{13}$

However, there is evidence that the p300/CBP coactivator family is also involved in the process of E1Ainduced activation of E2F1. Recently, the E1A protein was shown to possess an activation domain at its N-terminus, which spans $\mathrm{CR} 1^{14}$ and shows sequence similarity to the E2F1 activation motif. Both activation domains contain binding sites for $\mathrm{RB}$ and the p300/CBP coactivator family. ${ }^{15}$ p300/CBP was shown to contact the E2F1 activation domain both in vitro and in vivo, resulting in an increased activity of the E2F1/DP1 heterodimer. ${ }^{16,17}$ Mutation of the p300 binding site in E1A was shown to reduce its ability to activate E2F-regulated promoters even though this mutant still binds RB. ${ }^{15}$ Since both p300 and CBP possess intrinsic nucleosomal histone acetyltransferase (HAT) activity, ${ }^{18}$ induction of HAT enzymatic activity by direct binding to $\mathrm{E} 1 \mathrm{~A}^{19}$ might be a possible mechanism for E2F stimulation.

Most studies have focused on the involvement of p53 in regulating $\mathrm{E} 1 \mathrm{~A}$-induced apoptosis. It is well known that $\mathrm{E} 1 \mathrm{~A}$ 
A

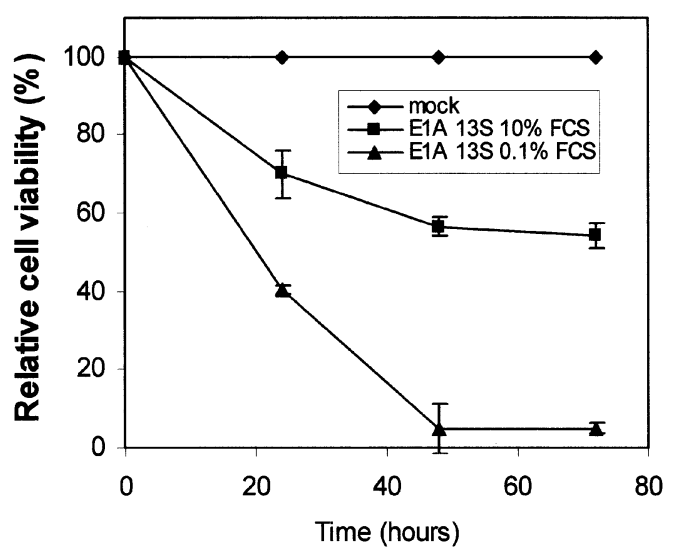

B

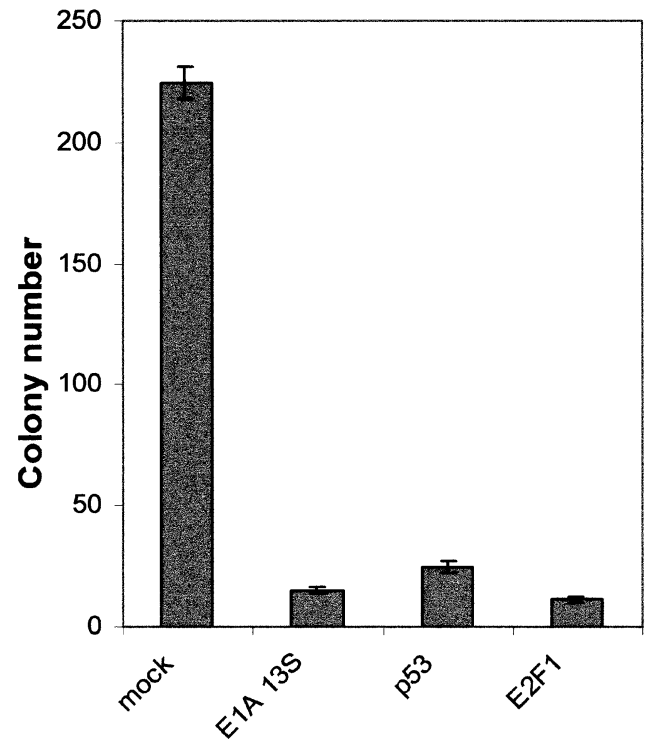

Figure 1 Analysis of cytotoxicity in p53-negative SK-OV-3 cells transiently transfected with E1A 13S. (A) After selection for transfected cells with puromycin, relative cell viability was measured by MTT assay in the presence $(10 \% \mathrm{FCS})$ and absence $(0.1 \% \mathrm{FCS})$ of serum at $24 \mathrm{~h}$-intervals over a period of 3 days relative to control plasmid (mock) transfected cells. Mock transfection with and without serum was set as $100 \%$. (B) Colony formation assay. The number of colonies in E1A-, p53-, and E2F1-transfected cells following puromycin-selection is shown compared to mock transfection. Colonies were stained and counted under light microscopy

can increase p53 levels which correlates with the ability to promote p53-dependent apoptosis in MEFs ${ }^{20,21}$ and tumor suppression in murine melanoma cells. ${ }^{22}$ Previous studies have shown that accumulation of p53 and induction of apoptosis by the E1A 12S protein is prevented by deletions within CR1 and the amino terminus, providing experimental evidence that participation of complex formation with $\mathrm{RB}$, p300 or both, are involved in p53-dependent apoptosis. ${ }^{23,24}$ E1A signaling to p53 through a pathway involving $R B$ inactivation requires the tumor suppressor protein p19ARF ${ }^{25}$ As published recently, E2F1 activates expression of the human p19 $9^{\mathrm{ARF}}$ homolog $\mathrm{p} 14^{\mathrm{ARF}},{ }^{26}$ which in turn blocks MDM2-induced p53-degradation by physical asso- ciation with the MDM2-p53 complex. ${ }^{27,28}$ Consistently, enforced expression of either E1A or E2F1 in MEFs induced $A R F$ gene expression leading to p53-dependent apoptosis. $^{25}$

Beside p53-dependent, p53-independent apoptosis is likely a major mechanism for inducing cell suicide. Several studies indicated a lack of correlation between p53 protein level and sensitivity to DNA-damaging agents in E1Atransfected cells, suggesting that E1A oncogene products may induce apoptosis also by pathways unrelated to p53. ${ }^{29,30}$ It has been shown that the E1A 13S protein induces apoptosis in cell lines lacking p53 during adenoviral infection. ${ }^{31}$ Important is that this p53-independent process requires the expression of one or more additional viral proteins. ${ }^{31}$ In detail, expression of the E4 gene products which are synthesized in response to transactivation by the large E1A protein was shown to be important. $^{31,32}$ From the E4 proteins, E4orf4 is the only product capable of independent cell killing. ${ }^{33}$ An adenovirus vector lacking both $\mathrm{E} 1$ and $\mathrm{E} 4$ is unable to induce DNA degradation and cell killing in an E1A-expressing cell line. ${ }^{32}$ However, p53-independent apoptosis induced by the E1A $13 \mathrm{~S}$ product in the context of a virus that contains an intact E4 region is associated with activation of procaspase- $3,{ }^{34}$ whereas E4orf4 expressed from a heterologous promoter does not result in activation of caspase- $3^{35}$ common to most apoptosis-inducing events. This suggests that $\mathrm{E} 1 \mathrm{~A}$ $13 S$ contributes to more than one apoptosis signaling event within the p53-null context.

In this study we show that Ad5 E1A by itself has p53independent apoptotic activities in human cells. Important is that in contrast to the current opinion, this apoptotic function does not require other adenoviral gene expression. We show that the same classes of proteins, RB and p300, involved in E1A-mediated transformation are also responsible for induction of apoptosis by $\mathrm{E} 1 \mathrm{~A}$ in a system that lacks p53. Our data also demonstrate a direct correlation between down-modulation of the p53-independent apoptotic activity and transformation efficiency in primary mouse cells.

\section{Results}

\section{E1A by itself induces enhanced cytotoxicity in p53 negative cells}

E1A expression has been shown previously to enhance in vitro cytotoxicity to ionizing radiation and chemotherapeutic agents, ${ }^{22,29}$ and this sensitization was regarded as p53dependent. ${ }^{20}$ However, high levels of p53 protein are not always associated with sensitivity to DNA-damaging agents, ${ }^{29}$ suggesting that $\mathrm{E} 1 \mathrm{~A}$ may affect other cellular pathways involved in enhanced cytotoxicity. To directly assess the cytotoxic effect of the E1A 13S protein without interference from other viral gene products in the absence of p53, we used SK-OV-3 cells previously shown to be negative for p53-protein expression. ${ }^{36}$ To obtain highest transduction efficiency, cells were transfected by electroporation with plasmid DNA containing the coding sequence of E1A $13 \mathrm{~S}$. Transfected cells were selected for puromycin resistance. 
A

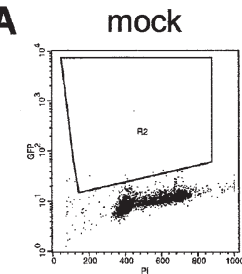

B

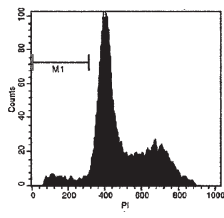

mock
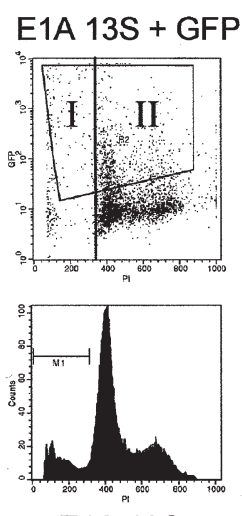

E1A $13 S$
C
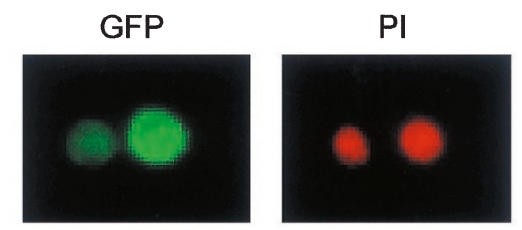

I
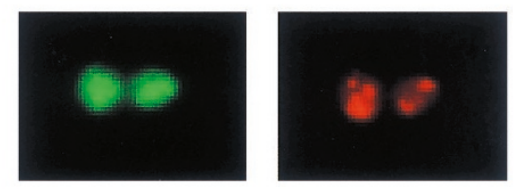

Figure 2 Ectopic expression of E1A 13S triggers apoptosis independent of p53. FACS analysis (A, B) and fluorescence microscopy (C) of E1A 13S and control plasmid transfected SK-OV-3 cells (mock). For FACS analysis, transfected cells were gated based on GFP-expression (A-C). Apoptosis was measured by the accumulation of cells with a sub-G1 DNA content, indicated as M1, $72 \mathrm{~h}$ following transfection (B). GFP-positive cells were sorted out by FACS based on PI fluorescence (DNA content). Apoptotic nuclei of cells representative for the sub-G1 fraction, indicated as I (A) are shown by fluorescence microscopy (C). Nonapoptotic cells from the G1, S, G2/M population are labeled as II

Cytotoxicity was analyzed by quantitating viable cells in presence and absence of serum using the MTT assay. As shown in Figure 1A, E1A protein expression resulted in a significant loss of cell viability by approximately $50 \%$ at day 3 , compared to control vector (mock) transfected cells which were set as $100 \%$. Serum starvation already had a certain effect on the viability of mock-transfected cells. To evaluate the effect of E1A compared to control vector in absence of serum, mock-transfection was again set as $100 \%$. Cell killing induced by $\mathrm{E} 1 \mathrm{~A}$ alone was found to be greatly enhanced in serum-deprived SK-OV-3 cells with a decrease in cell viability by more than $90 \%$ after 2 days. The ability of E1A to mediate p53-independent cytotoxicity was confirmed in comparison to the apoptosis-inducing proteins p53 and E2F1 by colony formation assay (Figure 1B). A significant reduction in the number of colonies was seen in E1A 13S-transfected cells. The colony number was lower than in cells transfected with p53, suggesting that $E 1 A$, at least under cell culture conditions, is more effective in inducing cell death. The results, however, indicate that the number of colonies seen with E1A was similar to or slightly higher than in E2F1transfected SK-OV-3 cells. In all colony formation assays, transfection efficiency assessed by immunofluorescence was comparable (data not shown).

\section{E1A-mediated cell death is caused by apoptosis independent of p53}

To investigate whether the observed loss of viability in p53negative cells upon overexpression of $\mathrm{E} 1 \mathrm{~A}$ protein is due to apoptosis, the transfected SK-OV-3 cell population was further analyzed using FACS (Fluorescence Activated Cell Sorter) analysis of propidium iodide (PI)-stained cells (Figure 2A). Quantification of sub-G1 cells at $72 \mathrm{~h}$ posttransfection using plasmid DNA encoding E1A 13S clearly revealed an elevated apoptotic rate in $E 1 A$ expressing, GFP-positive SK-OV-3 cells with an eightfold increase in apoptosis, compared to cells transfected with the control vector (Figure 2B). The nuclear morphology of E1Atransfected SK-OV-3 cells was analyzed by fluorescence microscopy of cells sorted out by FACS from the sub-G1 fraction at $72 \mathrm{~h}$ following transfection. E1A expression in these cells produced typical apoptotic features with striking changes in the nuclear morphology, characterized by intense staining of condensed chromatin and nuclear fragmentation (I; Figure 2C). In contrast, nuclei of transfected SK-OV-3 cells sorted out from the G1, S, G2/ $\mathrm{M}$ population showed a regular morphology (II; Figure 2C).

It has been shown previously that some apoptotic processes are inhibited by serum factors and that serumstarvation increased apoptosis in E1A-expressing cells in the presence of $p 53 .^{20}$ To establish the contribution of serum-depletion on the apoptotic function of $E 1 A$ in the absence of p53, apoptosis was further analyzed in E1Atransfected Saos-2 cells grown with and without serum. A typical DNA laddering pattern consistent with apoptosis was evident in serum-starved Saos-2 cells transfected with the E1A $13 S$ expression plasmid at day 3, comparable to DNA fragmentation observed in the sample following treatment with the apoptosis inducing DNA damaging agent etoposide (Figure $3 \mathrm{~A}$ ). In contrast, cells introduced with control plasmid in serum-free medium showed only a band at a high molecular weight corresponding to intact DNA. Compared to E1A-transfected Saos-2 cells in the presence of serum, the population of sub-G1 cells quantitated by flow cytometry significantly increased following serum depletion at 48 and $72 \mathrm{~h}$ post-transfection using calcium-phosphate (Figure $3 \mathrm{~B}, \mathrm{C}$ ) which correlates with $\mathrm{E} 1 \mathrm{~A}$-induced cytotoxicity following serum starvation shown in Figure 1A. At $72 \mathrm{~h}$ post-transfection more than $40 \%$ of growing Saos- 2 cells introduced with E1A showed a sub-G1 DNA content in FACS analysis. However, no difference in the apoptotic rate was observed between calcium-phosphate transfected cells or cells transfected by electroporation (see Figure 4A). In the absence of serum, $\mathrm{E} 1 \mathrm{~A}$ expression resulted in a moderate but significant 
increase of cells in the S-phase (Figure 3B), indicating that E1A-transfected cells were able to overcome a serum starvation induced accumulation in G1. The fact that the solitary delivery of E1A leads to an enhanced apoptotic
A

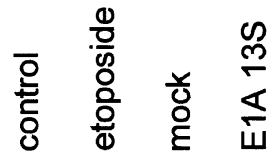

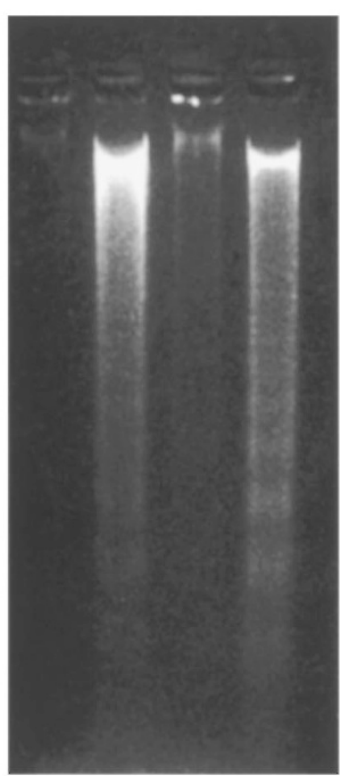

B

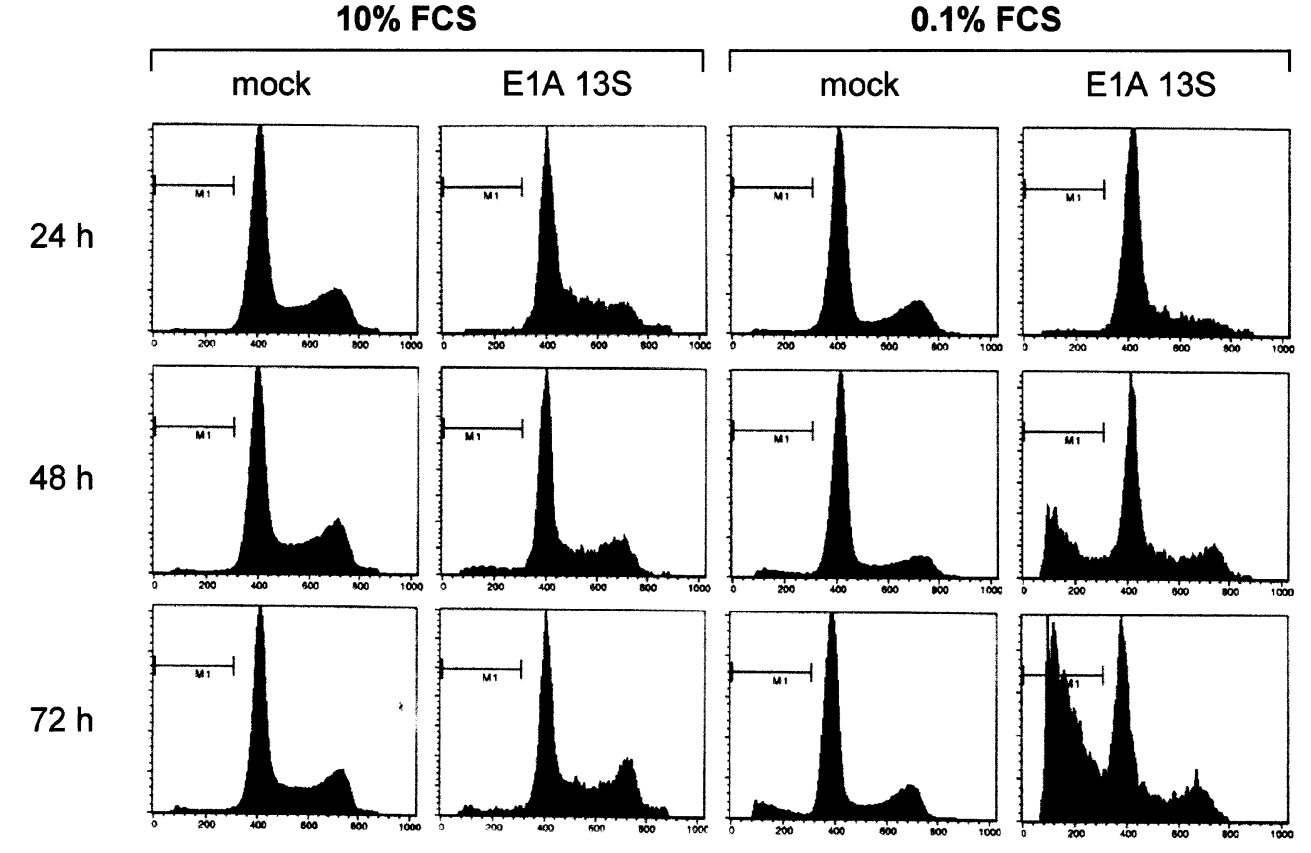

Figure 3 The apoptotic function of E1A in p53-negative cells is enhanced by serum depletion. DNA fragmentation (A) and FACS analysis (B, C) of Saos-2 cells transiently transfected with plasmid DNA containing the coding sequence of E1A $13 S$ or control vector (mock) by electroporation (A) or using the calcium phosphate procedure shown in (B, C). Low molecular weight DNA of E1A-transfected cells, or cells treated with etoposide after serum depletion (0.1\% FCS) was analyzed by agarose gel electrophoresis at $72 \mathrm{~h}(\mathbf{A})$. Apoptosis was measured by the accumulation of cells with a sub-G1 DNA content, labeled as M1 (B). The graph (C) represents the percentage of cells with sub-G1 DNA content (apoptotic cells) in transfected Saos-2 cells expressing E1A or mock in presence (10\% FCS) or absence $(0.1 \% \mathrm{FCS})$ of serum measured on three consecutive days following transfection. The mean values were derived from two independent experiments 
A

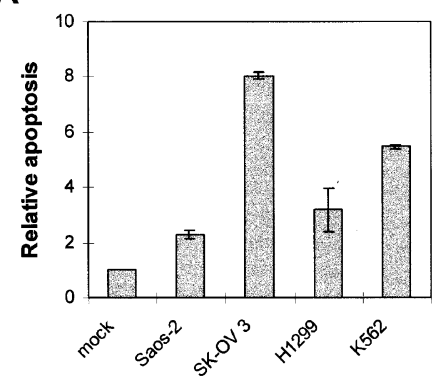

B

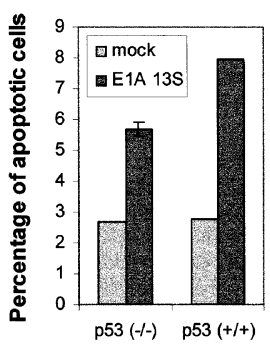

Figure 4 E1A $13 S$ induces apoptosis in various p53-null cells. (A) p53negative human tumor cell lines were transiently transfected with $E 1 A$ or control plasmid (mock) and subjected to FACS analysis. Relative apoptosis in the presence of serum $72 \mathrm{~h}$ following transfection is as indicated. The increase of apoptosis (as determined by cells with a sub-G1 DNA content) was calculated by subtraction of the percentage of apoptotic cells seen in the population by electroporation alone. Apoptosis in mock transfected cells (4.7\% sub-G1 in SK-OV-3 cells, 4.7\% in Saos-2, 5.4\% in $\mathrm{H} 1299$ and $8.2 \%$ in K562) was set as 1. The graph represents the mean of two independent experiments. (B) Apoptosis in primary E1A-transfected BMK cells from p53-negative compared to p53-wild-type mice was analyzed by FACS analysis as described in $(\mathbf{A})$

response independent of p53 was confirmed in two additional p53-null human tumor cell lines, H1299 and K562, shown in Figure 4A.

In addition we analyzed the proapoptotic effect of E1A expression in non-tumor cells. Primary baby mouse kidney (BMK) cells were transfected with $\mathrm{E} 1 \mathrm{~A}$ and subsequently subjected to FACS analysis. In p53-negative BMK cells $\mathrm{E} 1 \mathrm{~A}$ led to a more than twofold increase in apoptosis compared to an approximately threefold increase in p53wild-type BMK cells (Figure 4B). Increased apoptosis in p53-wild-type cells is consistent with previous data, ${ }^{20}$ nevertheless our data underline the significant role of p53-independent apoptosis in primary cells.

\section{Apoptosis induced by E1A involves PARP cleavage and can be inhibited by ZVAD-fmk, $\mathrm{E} 1 \mathrm{~B} 19 \mathrm{~K}$ and $\mathrm{Bcl}-2$}

To initially characterize the signaling pathway implicated in E1A-mediated p53-independent apoptosis, we analyzed the processing of procaspase-3 (pro-CPP32), a member of the Ced-3/ICE protease family, into the active $17 \mathrm{kD}$ and $12 \mathrm{kD}$ subunits. Caspase-3 (CPP32) cleaves poly(ADP-ribose) polymerase (PARP) and plays a key role in mammalian apoptosis. ${ }^{37}$ One problem with transient transfection experiments is the difficulty to detect particularly short-lived proteins in a relatively small number of transfected cells in front of the untransfected background. Therefore, to determine the effect of E1A-expression in SK-OV-3 cells, Western blot analysis was performed using whole cell extract prepared from the GFP-positive, transfected population sorted out by FACS. In these cells, stimulation of apoptosis by $E 1 A$ triggered processing of procaspase-3, as revealed by the appearance, albeit weakly, of a $\sim 17 \mathrm{kD}$ product which corresponds to the $17 \mathrm{kD}$ subunit of activated caspase-3 (Figure $5 \mathrm{~A}$ ). As shown in Figure $5 A$, induction of apoptosis by E1A was also accompanied by cleavage of the $116 \mathrm{kD}$ intact form of PARP to the $85 \mathrm{kD}$ fragment intimately linked to the induction of apoptosis in other systems. Interestingly, the apoptotic activity of E1A in p53-null SK-OV-3 cells, measured by flow cytometry analysis at $72 \mathrm{~h}$ post-transfection, was significantly antagonized by the wide-spectrum caspase-inhibitor, zVAD-fmk, resulting in a $\sim 50 \%$ reduction of apoptosis (Figure $5 \mathrm{~B}$ ). This is different from recent observations about p53-independent apoptosis triggered by the E4orf4 protein. Expression of E4orf4 does neither involve caspase-3 and PARP activation nor is apoptosis inhibited by zVAD-fmk, ${ }^{35}$ suggesting that activation of CPP32 described for apoptosis by E1A 13S in the viral context ${ }^{34}$ may be attributable to the apoptotic potential of E1A alone.

Furthermore, we sought to establish whether the apoptotic function of $\mathrm{E} 1 \mathrm{~A}$ alone is prevented by general suppressors of apoptosis, as Bcl-2 and its functional equivalent, the adenoviral E1B19K (19K), both of which act downstream of p53 by suppressing both p53-dependent and p53-independent apoptotic pathways. ${ }^{38}$ In contrast, the E1B55K (55K) protein blocks p53-mediated cell death by direct binding to p53 and thereby impairing its ability to regulate expression of genes implicated in apoptosis. ${ }^{39}$ Therefore, the $55 \mathrm{kD}$ protein should not affect apoptosis by $\mathrm{E} 1 \mathrm{~A}$ in the absence of p53. As shown in Figure 5C, E1A induced cell death is clearly suppressed by coexpression of either $19 \mathrm{~K}, \mathrm{E} 1 \mathrm{~B}$ or Bcl-2, but not 55K. Compared to E1A, none of the $\mathrm{E} 1 \mathrm{~B}$ proteins or $\mathrm{Bcl}-2$ alone possessed apoptotic activity (data not shown). However, failure to show any effect of $55 \mathrm{~K}$ on E1A-induced apoptosis was not attributable to the lack of protein expression, as similar levels of $19 \mathrm{~K}, \mathrm{Bcl}-2$ (Figure 5D) and 55K (Figure 5E) were detected in E1A-expressing SK-OV-3 cells cotransfected with these plasmids.

\section{p53-independent apoptotic activity of E1A requires binding of both $\mathrm{p} 300$ and $\mathrm{RB}$}

In an attempt to understand the mechanism of E1A-mediated p53-independent apoptosis, we tested the apoptotic function of a number of previously characterized E1A mutants (Figure 6A, left panel) carrying mutations that interfere with the binding of p300/CBP, RB and related proteins known to mediate specific E1A functions. ${ }^{15,21,40,41}$ Mutant $13 S \cdot \Delta C R 1$ lacks essential binding sites for $\mathrm{p} 300$ which results in the loss of $\mathrm{p} 300$ binding. Despite its ability to associate with RB, it is defective in RB-E2F dissociation ${ }^{13}$ as shown by immunoprecipitation of stable E1ARB-E2F1 complexes (Figure 6B, lane 4). Mutant 13S. $\Delta \mathrm{CR} 2$ interacts with p300 normally but is deleted in the primary $R B$ binding site in $\mathrm{CR} 2$ and thus unable to form complexes with $\mathrm{RB}$ and E2F1 (Figure 6B, lane 5), which is consistent with data obtained by Querido et al ${ }^{24}$ E1A $12 S$ lacks CR3 but binds to both p300 and the RB pocket protein. Mutants 12S.RG2 and 12S. $\Delta 64-68$ contain modifications of amino-terminal and CR1-located p300-binding sites, respectively. Thus, both are defective in interaction with p300, whereas binding the RBrelated proteins is unimpaired. ${ }^{40}$ The ability of $p 300, R B$ and E2F1 to bind to the various E1A mutant proteins is shown in Figure 6B. All E1A-mutants except for $13 \mathrm{~S} \cdot \Delta \mathrm{CR} 1$ and 13S. $\triangle \mathrm{CR} 2$, precipitated only a small amount of E2F1 (lanes $1,3,6-8)$ which can be explained by unstable E1A-RB-E2F1 
A

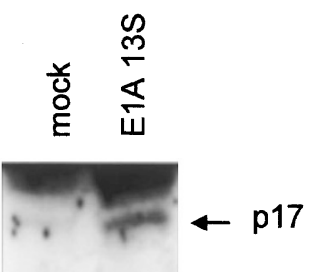

Caspase-3

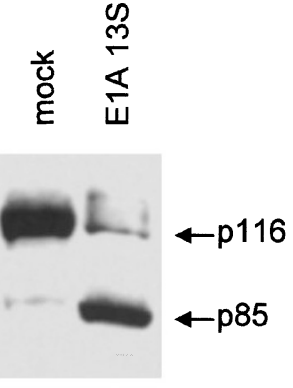

PARP

\section{C}

\section{Percentage of apoptotic cells}

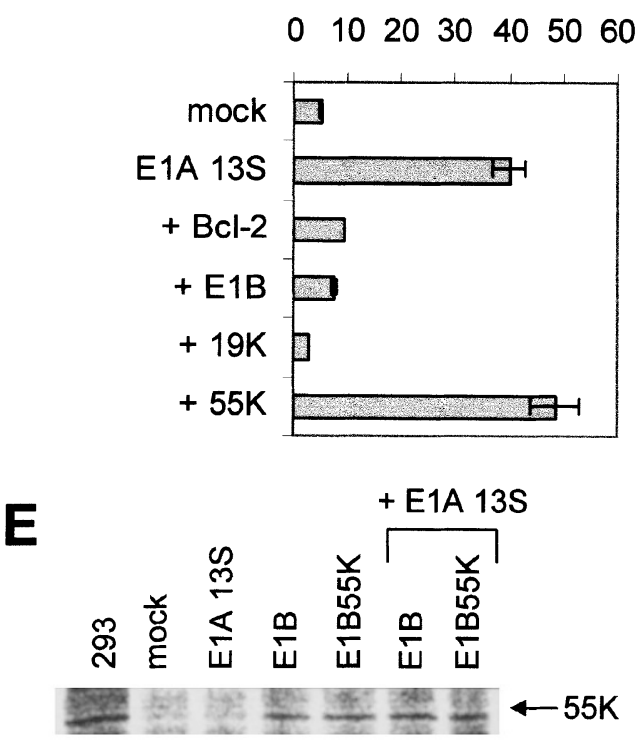

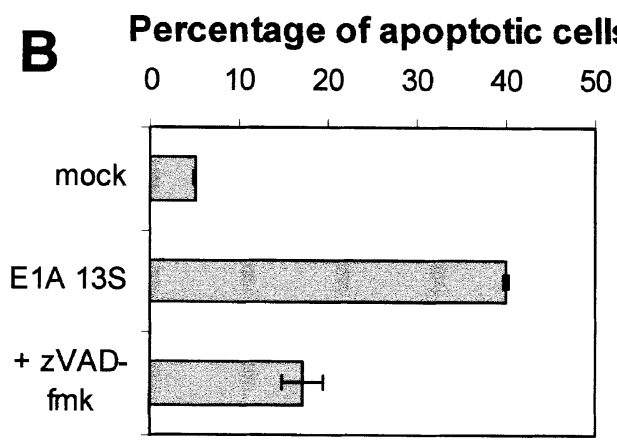

D
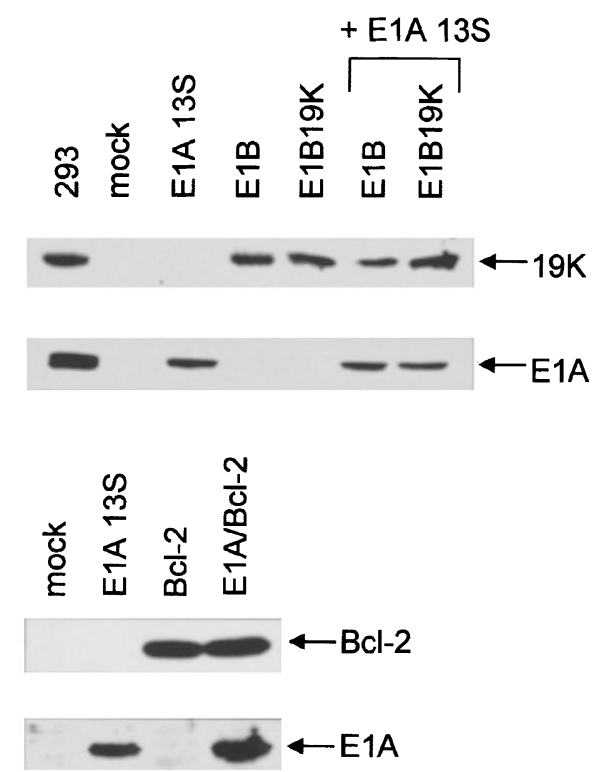

Figure 5 Characterization of the signaling pathway involved in E1A-induced apoptosis in p53-negative SK-OV-3 cells. Activation of Caspase-3 (CPP32) and PARP cleavage in cells transiently transfected with E1A or control plasmid (mock) were analyzed by Western blot (A). Equal amounts of whole cell extracts from GFP-positive cells sorted out by FACS were separated by SDS-PAGE. Full-length caspase-3 and the cleaved $17 \mathrm{kD}$ subunit as well as PARP (116 kD) and the $85 \mathrm{kD}$ proteolytic cleavage product are indicated by arrows. FACS analysis (B, C) demonstrates that ZVAD-fmk $(50 \mu \mathrm{M})$ can specifically inhibit E1A $13 S$ plasmid induced apoptosis (B) and that the apoptotic function of E1A can be overcome by coexpressed E1B, E1B19K and Bcl-2 protein (C). Percentage of apoptotic cells as determined by FACS analysis in the presence of serum is shown $72 \mathrm{~h}$ following transfection. The graph represents the mean of two to four independent experiments. (D) Western blot analysis and (E) immunoprecipitation of cells shown in (C) demonstrating expression of E1A, E1B19K (D; upper panel), E1A, Bcl-2 (D; bottom panel) and E1B55K (E). The positions of 19K, 55K, Bcl-2 and E1A protein are labeled

intermediates, described in Fattaey et al. ${ }^{13}$ This is consistent with the function of E1A in RB-E2F complex dissociation.

The apoptotic function of E1A and the various mutants was analyzed by flow cytometry in transiently transfected SKOV-3 cells. Based on FACS analysis shown in Figure 6A (right panel), the $12 \mathrm{~S}$ gene product of $\mathrm{E} 1 \mathrm{~A}$ that retained $\mathrm{RB}$ and p300 binding activities caused apoptosis to high levels comparable with E1A 13S. Since the $12 S$ protein lacks the $\mathrm{CR} 3$ region of $\mathrm{E} 1 \mathrm{~A}$, it appeared that $\mathrm{CR} 3$ is not involved in p53-independent apoptosis by E1A alone, which is different from the known p53-independent mechanism of E1Ainduced apoptosis in the context of a viral infection. In contrast, the mutants $12 \mathrm{~S} \cdot \mathrm{RG} 2$ and $12 \mathrm{~S} \cdot \Delta 64-68$ or $13 \mathrm{~S} \cdot \Delta \mathrm{CR} 2$ that had either lost their p300 binding activity due to a deletion in one of the p300 binding domains, or the ability to efficiently interact with RB, showed although still active a comparable significant decrease in the proportion of apoptotic cells compared to that seen in cells transfected with E1A 13S/12S. This suggests that the apoptotic function of $\mathrm{E} 1 \mathrm{~A}$ in the absence of p53 is likely associated with the ability to bind both $\mathrm{p} 300$ and RB. This observation was confirmed by overexpression of the mutant 13S. $\Delta \mathrm{CR} 1$, defective for $\mathrm{p} 300$ binding and also unable to dissociate RB-E2F complexes, which completely failed to induce apoptosis. Interestingly, even though the E1A mutants that lost either p300 or RB binding activity were able to induce apoptosis, full apoptotic activity of E1A $13 S$ could not be restored by cotransfection of 13S. $\triangle \mathrm{CR} 2$ and 12S.RG2 where the E1A binding sites were 
A
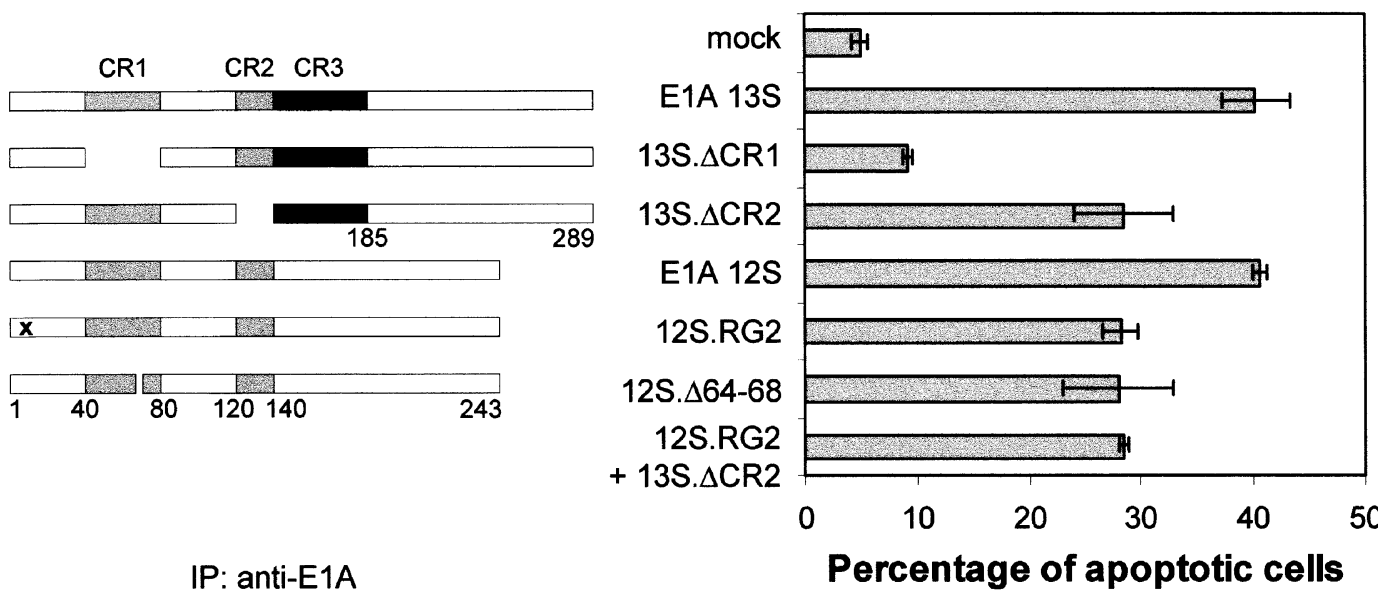

B
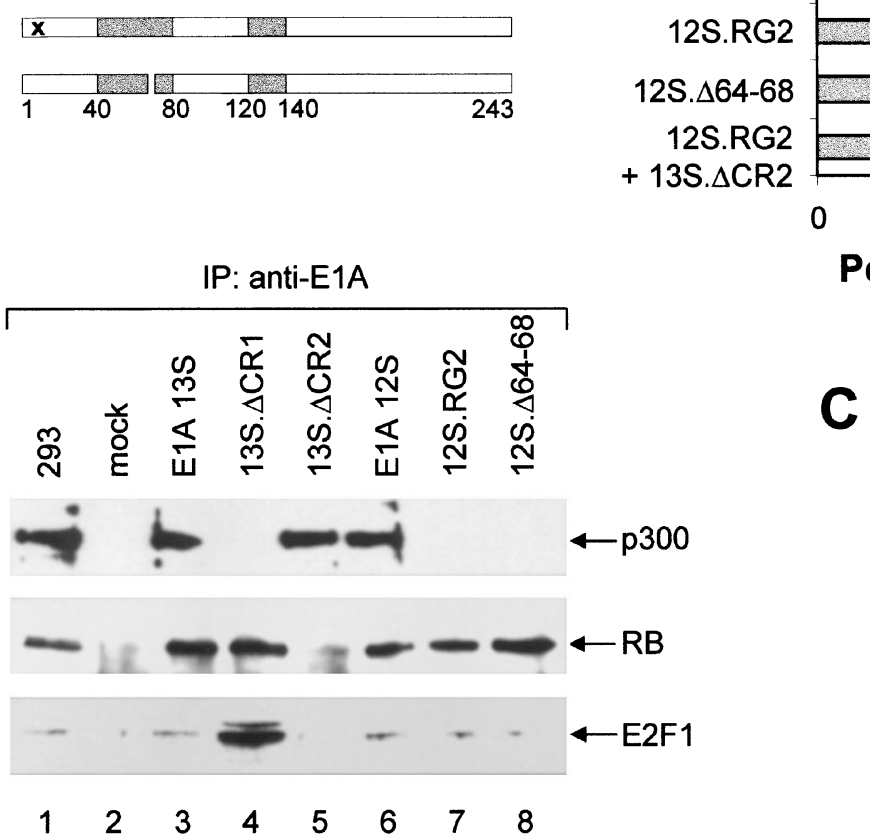

C

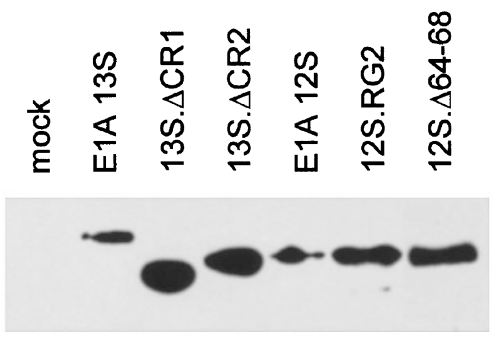

Figure 6 Characterization of E1A mutants in SK-OV-3 cells. (A) Schematic diagram of E1A mutants used in this study (A, left panel). Positions of the conserved regions $C R 1, C R 2$ and $C R 3$ of $E 1 A 13 S$ are marked. Deletions in the E1A mutants are indicated by gaps, and point mutations by an ' $\mathrm{X}$ '. $13 \mathrm{~S} \cdot \Delta \mathrm{CR} 1,13 \mathrm{~S} \cdot \Delta \mathrm{CR} 2$ and $12 S \cdot \Delta 64-68$ are deletions of amino acids $40-80,120-140$ and $64-68$, respectively. $12 S \cdot R G 2$ mutant has a substitution of a glycine for arginine at amino acid 2 . (A, right panel) Percentage of apoptotic cells in the presence of serum $72 \mathrm{~h}$ following transient transfection of $\mathrm{E} 1 \mathrm{~A}$ mutant plasmids analyzed by FACS. The graph represents the mean of two to four independent experiments. The ability of p300, RB and E2F1 to bind to the E1A mutant proteins, immunoprecipitated with M73 antibody is as indicated (B). The positions of p300, RB and E2F1 are labeled. (C) Western blot analysis of the expression levels of E1A and its mutants shown in (A)

separated on different molecules. This suggests that full E1Ainduced apoptosis requires both p300 and RB binding sites on the same molecule. Together, these data implicate that the same classes of proteins, p300 and RB, involved in E1Amediated p53-dependent apoptosis (24) are also responsible for induction of apoptosis in a system that lacks p53. As an indication of the transfection efficiency, E1A expression of the mutants was monitored by Western blot analysis (Figure 6C). Slightly lower E1A protein expression levels of E1A 13S and $E 1 A 12 S$ correlated with their ability to efficiently induce apoptosis and was not likely to be due to differences in E1A production.

\section{The apoptotic function of E1A is specifically inhibited by $R B$}

A considerable body of evidence argues that p53dependent and independent mechanisms contribute towards E2F1-induced apoptosis through pathways in which the apoptotic activity of E2F1 is governed by RB. ${ }^{6,42}$ Since direct binding of $\mathrm{RB}$ to $\mathrm{E} 2 \mathrm{~F} 1$ is required to block apoptosis induced by $\mathrm{E} 2 \mathrm{~F} 1,{ }^{42}$ and $\mathrm{E} 1 \mathrm{~A}$ inactivates $\mathrm{RB}$ by dissociating RB-E2F1 complexes, E1A-induced apoptosis should be inhibited by the coexpression of RB. To address this question, wild-type $R B$ was introduced together with $E 1 A$ $13 \mathrm{~S}$ into SK-OV-3 cells (Figure 7B) and Saos-2 cells (Figure 7A) that express a carboxy-terminally truncated form of RB which is defective for E2F binding. ${ }^{43}$ For coexpression, we chose the same amount of RB plasmid DNA which was sufficient to induce a G1-arrest in RBtransfected cells (data not shown). As confirmed by FACS analysis, E1A-induced apoptosis in both cell lines was indeed specifically inhibited by the coexpression of RB to levels seen in mock transfected cells. In support of our suggestion, the mutant RB $\Delta$ ex22, which lacks the region required for $\mathrm{E} 2 \mathrm{~F} 1$ binding failed to suppress the apoptotic activity of E1A (Figure 7, left panels). Failure of RB $\Delta$ ex22 to inhibit E1A-induced apoptosis was not due to the lack of expression (Figure 7, right panels). In RB-negative Saos-2 cells, the apoptotic rate seen in E1A-transfected cells is 
A
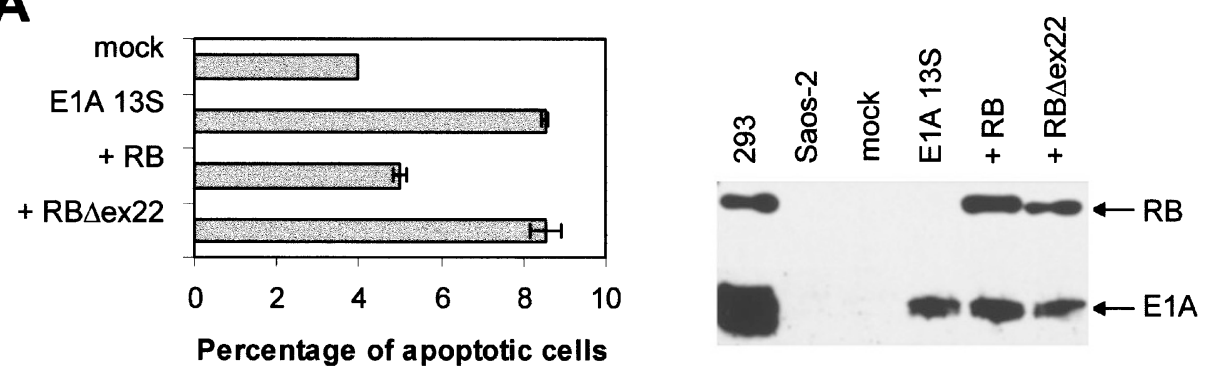

B
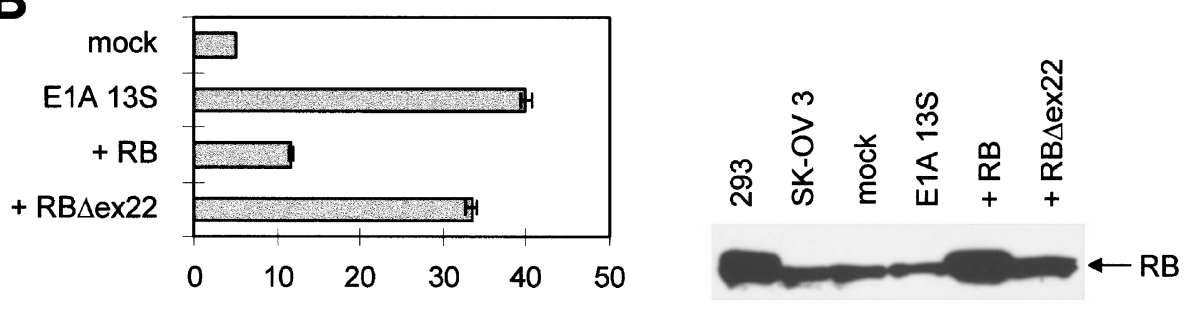

Percentage of apoptotic cells

Figure 7 E1A-induced apoptosis is specifically inhibited by RB. Saos-2 (A) and SK-OV-3 cells (B), transiently transfected with the E1A 13S plasmid, were cotransfected either with RB or the RBAex22 mutant expression plasmid and analyzed by FACS. Percentage of apoptotic cells in the presence of serum $72 \mathrm{~h}$ following transfection is indicated in the left panels. The graph represents the mean of two to four independent experiments. The expression levels of RB and RB mutant in Saos-2 and SK-OV-3 cells transfected with E1A are shown in the right panels. The positions of E1A and RB are as indicated

most likely attributable to E1A-induced dissociation of E2F complexes with the RB related proteins p107 and p130.

\section{E1A-induced focus formation of p53 negative primary rodent cells is enhanced by the antiapoptotic activity of E1B and E1B19K}

Since coexpression of $\mathrm{E} 1 \mathrm{~A}$ with antiapoptotic proteins like $\mathrm{E} 1 \mathrm{~B}, \mathrm{Bcl}-2$ or $\mathrm{H}$-ras, is necessary for efficient transformation and can overcome p53-dependent E1A-induced apoptosis ${ }^{38}$ it is speculated that disruption of the p53-dependent fail-safe mechanism that normally protects cells from oncogenic signals, enables $\mathrm{E} 1 \mathrm{~A}$ to function as a pure growth promoter. If $p 53$ is required for induction of apoptosis by $E 1 A$, one would expect to see efficient transformation by $\mathrm{E} 1 \mathrm{~A}$ alone in p53 $(-I-)$ primary BMK cells. Thus, we analyzed to what extent E1B expression affects E1A-induced focus formation in p53null cells (Figure 8). Consistent with previously published results, ${ }^{44,45}$ transfection of the E1A plasmid into p53-null primary BMK cells resulted in a relatively small but higher number of foci than in p53 wild-type BMK cells (Figure 8), consistent with the data from our FACS analysis (Figure 4B). Cotransfection of E1A either with E1B or 19K significantly increased the frequency of transformation to an equal extent, implicating that in contrast to $\mathrm{p} 53$ wild-type cells $55 \mathrm{~K}$ had as expected no additional effect in p53-negative cells. These results suggested that abrogation of $E 1 \mathrm{~A}$-induced apoptosis by $19 \mathrm{~K}$ enhances transformation of p53-negative rodent cells. Together, the data support the idea that efficient transforma-

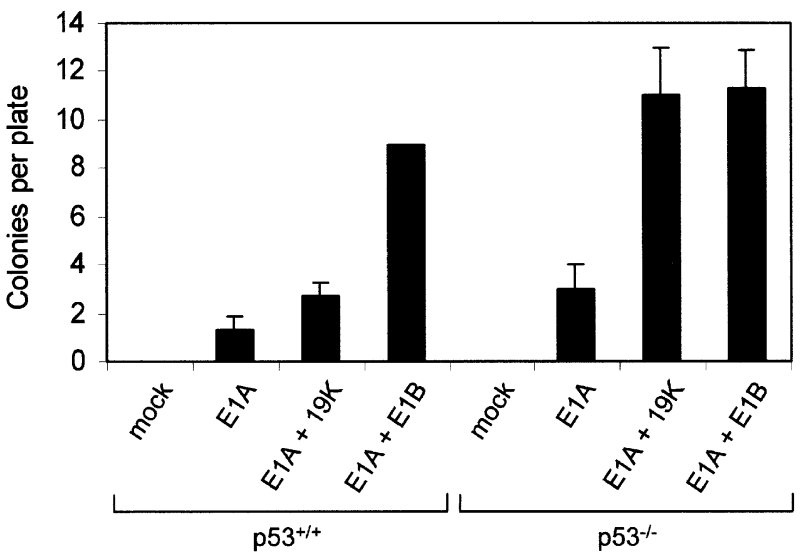

Figure 8 Suppression of focus formation by $\mathrm{E} 1 \mathrm{~A}$ expression. $\mathrm{p} 53^{-1-}$ and p53 ${ }^{+/+}$primary BMK cells were transfected with E1A 13S, E1A 13S $+19 \mathrm{~K}$ or E1A 13S+E1B plasmid DNA. Focus formation was determined 6-8 weeks after transfection by microscopy. The number of colonies represents the average \pm S.D. from three experiments

tion requires down-modulation of E1A-mediated p53-independent apoptosis.

\section{Discussion}

Apoptosis is a cell suicide mechanism culminating in an autocatalytic cellular degradation that can be triggered by a wide variety of stimuli. Although most studies have focused on 
the involvement of p53 in regulating apoptosis, it is clear from several reports that p53-independent mechanisms of apoptosis exist. ${ }^{46,47}$ In fact, many cell types are capable of executing apoptosis during embryogenesis through a route independent of p53, as p53-null mice develop normally and are generally able to maintain normal tissue homeostasis. ${ }^{48}$ With regard to tumorigenesis, studies of animal models revealed down-modulation of p53-independent apoptosis as a step in cancer development which contributes to the frequency of progression from the preneoplastic stage to solid tumors. ${ }^{2}$ Thus, it is obvious that apoptosis in the absence of p53 is likely to be a major component of most cells repertoire for inducing cell death. Considering that p53 remains the most frequent target for genetic alterations identified in human cancers, understanding the molecular basis for p53-independent apoptosis is essential. Previous reports indicated that $\mathrm{E} 1 \mathrm{~A}$ can induce both p53-dependent and, in the context of viral infection, p53-independent apoptosis. ${ }^{31,32} \mathrm{E} 1 \mathrm{~A}$, therefore, provides an interesting model to study the various mechanisms implicated in activating the cellular apoptotic machinery and the in vivo relevance of p53independent apoptosis for oncogenic transformation.

Here, we provide direct evidence that E1A 135 by itself is capable of inducing a substantial cytocidal effect by a mechanism that involves the classical hallmarks of apoptosis, thus contributing to a further independent apoptosis signaling event within the p53-null context. E1A 13S-induced apoptosis is considerably elevated in p53negative human tumor cells under the conditions of serum depletion. As previously shown, normal rat kidney cells underwent apoptosis when stimulated by E1A to proliferate under conditions where proliferation was blocked. ${ }^{23}$ In addition, elevated apoptosis was seen by transferring E2F1 in serum-deprived p53-negative human Saos-2 tumor cells. ${ }^{6}$ In both cases, apoptosis has been discussed as the result of conflicting signals generated by the proliferative signal mediated by $\mathrm{E} 1 \mathrm{~A}$ or $\mathrm{E} 2 \mathrm{~F} 1$, respectively, in the absence of exogenous growth factors. Our experiments in growing Saos- 2 cells indicated that apoptosis induced by E1A in the absence of serum was accompanied by a moderate acceleration of cells entering S-phase, indicating that E1A-transfected cells were able to overcome the serum starvation-induced G1-block. However, since we observed E1A-induced apoptosis also in the absence of a proliferation block, it is likely that E1A $13 S$ induces apoptosis at least in part by a mechanism separate from the induction by a proliferation block. Consistent with this, the p53-negative apoptotic function of E2F1 in Saos-2 cells was shown to be not dependent on transcription activation or the ability to accelerate entry into DNA synthesis, ${ }^{6}$ supporting the idea that E1A-induced apoptosis independent of p53 occurs through a similar or identical mechanism.

In the context of a virus, induction of p53-independent apoptosis by $\mathrm{E} 1 \mathrm{~A}$ requires viral $\mathrm{E} 4$ gene products $^{32}$ and involves a mechanism that includes activation of caspases. ${ }^{34}$ Although E4orf4 is the only E4 product capable of independent cell killing, it does not require activation of known zVAD-fmk-inhibitable caspases. ${ }^{35}$ Our results show that the induction of apoptosis by the solitary delivery of
E1A 13S into p53-null human tumor cells can be linked to the activation of caspase-3 (CPP32) and cleavage of PARP. Moreover, the cell death inducing activity of $E 1 \mathrm{~A}$ alone is prevented by the commonly used caspase-inhibitor zVAD-fmk. In light of these findings, we can interpret the processing of CPP32 and PARP cleavage observed by Boulakia et al. ${ }^{34}$ during adenoviral infection in p53-null cells as a direct consequence of the E1A $13 S$ function which does not require cooperation with other viral proteins to cause cell death.

Previous studies have shown that E1A-induced cell death occurring via a p53-dependent mechanism requires regions of E1A proteins associated with DNA synthesis and transformation. ${ }^{24,31}$ In primary MEFs ${ }^{21}$ and human tumor cells, ${ }^{24}$ p53 accumulation and apoptosis involves complex formation with either RB and/or p300. E1A mutants unable to bind p300 or the RB-family proteins were impaired in their ability to induce the tumor suppressor p19ARF, the homolog of human $\mathrm{p} 14^{\mathrm{ARF}}$, which modulates $p 53$ activity in response to $E 1 A^{25}$ as part of a fail-safe mechanism to protect against aberrant, oncogene mediated cell growth. ${ }^{26}$ In our attempt to determine the functional domains of $E 1 A$ responsible for apoptosis induction in the absence of $\mathrm{p53}$, the results demonstrate that the apoptotic activity of $\mathrm{E} 1 \mathrm{~A}$ is apparently reduced by deletions encompassing the binding regions for p300 in the amino terminus (12S.RG2) and CR1 (13S. $\Delta 64-68)$. In addition our results show that the RB-binding defective mutant $E 1 A \cdot \Delta C R 2$ induces approximately $50 \%$ less apoptosis than E1A.13S or $E 1 A \cdot 12 S$. RB has been shown recently to inhibit apoptosis induced by various agents in different cell systems including ionizing radiation, IFN- $\gamma$, p53 or E2F1-induced apoptosis. ${ }^{42,49}$ Consistent with the apoptosis protecting function of $\mathrm{RB}$ we were able to protect SK-OV-3 cells and functionally RBnegative Saos-2 cells from E1A-induced apoptosis by ectopic expression of RB. This implicates that the same classes of proteins, p300 and RB, involved in E1A-mediated p53dependent apoptosis ${ }^{24}$ are also responsible for induction of apoptosis in a system that lacks p53. In contrast to the mutants mentioned above, the double defective mutant $13 \mathrm{~S} \cdot \Delta \mathrm{CR} 1$, which is not only defective for p300 binding but also unable to dissociate RB-E2F complexes, completely failed to induce apoptosis. Since full apoptotic activity of E1A 13S could not be restored by cotransfection of the $E 1 A$ mutants $13 S \cdot \Delta C R 2$ and 12S.RG2, association between $\mathrm{p} 300$ and $R B$ in multimeric complexes seems to be required. ${ }^{16}$ As published recently, the interaction of $\mathrm{p} 300$ and $\mathrm{RB}$ with $\mathrm{E} 2 \mathrm{~F} 1$ has been shown to regulate the apoptotic activity of E2F1 in p53-negative Saos-2 cells, ${ }^{6,17,42}$ suggesting that by an E1A-induced assembly of p300, RB and E2F1, E1A switches E2F transcriptional activity from repression to activation. Our results are somehow in conflict with earlier data implicating that apoptosis induction by the 12S E1A gene product in Saos-2 cells during adenovirus infection might not require $\mathrm{RB}$ and $\mathrm{p} 300$ binding. ${ }^{50}$ Under conditions of infection, however, expression of apoptosismodulating $\mathrm{E} 4$ gene products is induced by cellular proteins that can functionally substitute for E1A CR3 as a transactivator of the early genes in human tumor cells, ${ }^{51}$ possibly interfering with regulation of $E 1 A$-induced apoptosis.

The E1A oncogene induces p53-dependent apoptosis through a mechanism involving inactivation of RB and up- 
regulation of the $A R F$-gene product. $^{25}$ Since $A R F$ is positively regulated by E2F1, deregulation of E2F1 activity by $\mathrm{E} 1 \mathrm{~A}$ is supposed to induce p53-dependent cell death upon $A R F$ induction. ${ }^{26}$ Supposing that p53-independent apoptosis induction by E1A is mediated by E2F1, activation of ARF might be required. The role of ARF in p53-negative cells is subject to further investigation.

As $\mathrm{p} 53$ is considered to be important in tumor surveillance, we finally analyzed the effect of this p53independent pathway on the transforming ability of E1A. Indeed, our data indicate that abrogation of E1Aassociated p53-independent apoptosis enhances immortalization of primary $\mathrm{p} 53^{(-1-)}$ baby mouse kidney cells. Netto tumor growth is determined by the balance of cellular proliferation and elimination of cells by apoptosis. One possible mechanism of shifting the balance towards cellular proliferation is disruption of the ARF-p53 pathway by loss of p53 function, but p53-independent mechanism(s) certainly contribute. Down-modulation of p53independent apoptosis is essential in the multistep process of cancer development, vice versa up-regulation of apoptosis by delivery of oncogenes as E1A or E2F1 suppresses growth of p53-negative tumors. ${ }^{30,52}$ Considering the accumulating evidence for the central role of E2F1 in regulating apoptosis in response to oncogenic stimuli, it will be interesting to further delineate the role of E2F1 in this p53-independent apoptotic pathway.

\section{Materials and Methods}

\section{Cell culture and plasmids}

Saos-2 cells, SK-OV-3, H1299 and primary baby mouse kidney (BMKs) cells were maintained in Dulbecco's modified Eagle medium (DMEM) supplemented with $10 \%$ fetal calf serum (FCS). K-562 cells were grown in RPMI medium plus $10 \%$ FCS. All cell lines were obtained from ATCC (Rockville, MD, USA). Primary $\mathrm{p} 53^{(-/-)}$BMK cells were prepared from 4-day-old 129/Sv-Trp53 ${ }^{\text {m1 Tyj }}$ mice (Jackson Laboratory, Bar Harbor, ME, USA) and the transformation assays were carried out as previously described. ${ }^{53}$ Transfection of BMK cells was performed by calcium phosphate-DNA precipitation. The Ad5 E1A cDNAs were cloned into pCMVneoBam for expression from the cytomegalovirus (CMV) promoter. The E1A deletion mutants 13S. $\Delta C R 1$ (del 40-80), 13S. $\Delta C R 2$ (del 120-140) and E1A 12S (del 140-185) were constructed by PCR using E1A 13S as template. The mutant 12S.RG2 was PCR-amplified by using the E1A $12 S$ as template, the $12 S \cdot \Delta 64-68$ construct (kindly provided by $T$ Kouzarides) was described previously. ${ }^{15}$ The expression constructs for p53, E2F1, RB and RB $\Delta$ ex22 (kindly provided by K Helin and WG Kaelin) have been described ${ }^{42,54,55}$ as have the $E 1 B$ expression plasmids for E1B, E1B19K and E1B55K (kindly provided by E White, ${ }^{56}$ ). For colony formation assay the cDNAs for E1A 13S, p53 and E2F1 were HAtagged. The $\mathrm{Bcl}-2 \mathrm{cDNA}$ (kindly provided by DW Andrews) was cloned into pcDNA3. Plasmid DNA was prepared by the alkaline lysis method and purified by $\mathrm{CsCl}$-ethidium bromide density gradient centrifugation.

\section{Immunoblotting}

Cell lysates were prepared following transfection and protein levels were analyzed by Western blot essentially as described. ${ }^{42}$ The antibodies used were against E1A (Oncogene Science M73), RB (Santa Cruz C15), p300 (Pharmingen NM11), E2F1 (Santa Cruz C20),
E1B19K (Calbiochem DP16), Bcl-2 (Santa Cruz 100), CPP32 17 kDa subunit (Santa Cruz E-8) and PARP 85 kDa (Pharmingen 7D3-6). CPP32 or PARP cleavage products were detected by using cell lysate from GFP-positive, transfected cells sorted out by flow cytometry analysis. Immune complexes were visualized by enhanced chemiluminescence (Amersham). To verify $\mathrm{RB}$ or p300 binding to the $\mathrm{E} 1 \mathrm{~A}$ mutant proteins, E1A-transfected cells were lysed in E1A lysis buffer (50 mM HEPES, pH 7.0, $250 \mathrm{mM} \mathrm{NaCl}, 0.1 \% \mathrm{NP} 40$ ) and immunoprecipitated with M73. Immunocomplexes were subjected to Western blot analysis. E1B55K from transfected, ${ }^{35}$ S-methionine labeled SK-OV-3 cells was immunoprecipitated as described previously ${ }^{36}$ with Ad5E1B-55K antibody (Calbiochem DP08).

\section{DNA transfection, MTT assay, colony formation assay and DNA fragmentation assay}

Unless otherwise stated, DNA was transfected into cells by the electroporation method. ${ }^{57}$ The ability of viable cells to reduce 3-4,5dimethylthiazol-2,5-diphenyl tetrazolium bromide (MTT) was determined essentially as described. ${ }^{58}$ Seven $\times 10^{6}$ SK-OV-3 cells were cotransfected with $10 \mu \mathrm{g}$ of the E1A $13 \mathrm{~S}$ expression plasmid and $1 \mu \mathrm{g}$ of the puromycin resistance gene containing plasmid. Twelve hours after transfection cells were washed and grown in medium containing $1 \mu \mathrm{g} / \mathrm{ml}$ of puromycin to select for transfected cells. After $36 \mathrm{~h}$ of selection, $2 \times 10^{4}$ viable cells were plated out in 96-well microtiter plates. Cell viability was determined in the presence and absence of serum after 1,2 and 3 days by the addition of $50 \mu \mathrm{l} \mathrm{MTT}(5 \mathrm{mg} / \mathrm{ml})$. Conversion of MTT to formazan was quantitated by measuring absorbance at $540 \mathrm{~nm}$. For colony formation assay, $10 \mu \mathrm{g}$ of plasmid DNA expressing E1A, p53 or E2F1 was transfected together with the puromycin- $\mathrm{N}$-acetyltransferase expressing plasmid into $1 \times 10^{6} \mathrm{SK}$ OV-3 cells in a $60 \mathrm{~mm}$ dish. Twenty-four hours after transfection, cells were washed and grown in puromycin containing medium $(1 \mu \mathrm{g} / \mathrm{ml})$ to select for resistant colonies. Resistant colonies were Giemsa stained 2-3 weeks after selection and counted under light microscopy. For the DNA fragmentation assay, Saos-2 cells were transfected with $10 \mu \mathrm{g}$ of the E1A plasmid DNA by electroporation. Six hours after the transfection cells were washed and grown in medium containing $0.1 \%$ of serum. As a positive control cells were treated with $34 \mu \mathrm{M}$ etoposide for $48 \mathrm{~h}$. Seventy-two hours after transfection both floating and attached cells were harvested and used for low-molecular-weight DNA extraction as described previously. ${ }^{59}$

\section{Flow cytometry and fluorescence microscopy}

Ten $\mu \mathrm{g}$ of plasmid DNA expressing $\mathrm{E} 1 \mathrm{~A}$ or $\mathrm{E} 1 \mathrm{~A}$ mutants and $2 \mu \mathrm{g} \mathrm{E} 1 \mathrm{~A}$ plasmid plus $8 \mu \mathrm{g}$ of RB, RB $\Delta \mathrm{Ex} 22, \mathrm{E} 1 \mathrm{~B}, 19 \mathrm{~K}$ or $55 \mathrm{~K}$ in cotransfection experiments were transfected into $7 \times 10^{6}$ cells. Where required, the peptide caspase-inhibitor Z-VAD-fmk (Calbiochem-Novabiochem) was added simultaneously with the apoptotic triggering signal at a final concentration of $50 \mu \mathrm{M}$. To measure the transfection efficiency $2 \mu \mathrm{g}$ of CMV-GFP reporter encoding the membrane-localized enhanced green fluorescence protein was cotransfected to ensure optimal fluorescence intensity in combination with ethanol fixation. ${ }^{60}$ To quantitate apoptosis by flow cytometry, floating and adherent cells were harvested $72 \mathrm{~h}$ post transfection, fixed in ethanol and stained for DNA content with propidium iodide. Cells were measured for green fluorescence intensity (channel FL-1) and propidium iodide fluorescence (channel FL-3) in a FACS sorter (FACSVantage, Becton Dickinson) using CELLquest software (Becton Dickinson). The cells that did not express GFP were used to set the baseline to allow the gating of the GFP-positive cells. The percentage of apoptotic cells seen in the population by electroporation alone (typically $2-4 \%$ with 
serum) was subtracted. For fluorescence microscopy ethanol fixed GFP-positive cells from either the sub-G1 or the G1, S, G2/M fraction were sorted by FACS into two populations based on their propidium iodide (PI) fluorescence (DNA content) and visualized by fluorescence microscopy.

\section{References}

1. White $E$ (1996) Life, death, and the pursuit of apoptosis. Genes Dev. 10: 1-15

2. Naik P, Karrim J and Hanahan D (1996) The rise and fall of apoptosis during multistage tumorigenesis: down-modulation contributes to tumor progression from angiogenic progenitors. Genes Dev. 10: 2105-2116

3. Sherr CJ (1996) Cancer cell cycles. Science 274: 1672-1677

4. Moran E (1993) Interaction of adenoviral proteins with $p R B$ and p53. FASEBJ. 7: $880-885$

5. Xiao ZX, Ginsberg D, Ewen M and Livingston DM (1996) Regulation of the retinoblastoma protein-related protein $\mathrm{p} 107$ by $\mathrm{G} 1$ cyclin-associated kinases. Proc. Natl. Acad. Sci. USA 93: 4633-4637

6. Phillips AC, Bates S, Ryan KM, Helin Kand Vousden KH (1997) Induction of DNA synthesis and apoptosis are separable functions of E2F-1. Genes Dev. 11: $1853-1863$

7. Weinberg RA (1995) The retinoblastoma protein and cell cycle control. Cell 81: $323-330$

8. Helin K, Harlow E and Fattaey AR (1993) Inhibition of E2F-1 transactivation by direct binding of the retinoblastoma protein. Mol. Cell. Biol. 13: 6501-6508

9. Flemington EK, Speck SH and Kaelin Jr WG (1993) E2F-1-mediated transactivation is inhibited by complex formation with the retinoblastoma susceptibility gene product. Proc. Natl. Acad. Sci. USA 90: 6914-6918

10. Brehm A, Miska EA, McCance DJ, Reid JL, Bannister AJ and Kouzarides T (1998) Retinoblastoma protein recruits histone deacetylase to repress transcription. Nature 391: 597-601

11. Magnaghi-Jaulin L, Groisman R, Naguibneva I, Robin P, Lorain S, Le Villain JP, Troalen F, Trouche D and Harel-Bellan A (1998) Retinoblastoma represses transcription by recruiting a histone deacetylase. Nature 391: 601-605

12. Ferreira R, Magnaghi-Jaulin L, Robin P, Harel-Bellan A and Trouche D (1998) The three members of the pocket proteins family share the ability to repress E2F activity through recruitment of a histone deacetylase. Proc. Natl. Acad. Sci. USA 95: $10493-10498$

13. Fattaey AR, Harlow E and Helin K (1993) Independent regions of adenovirus E1A are required for binding to and dissociation of E2F-protein complexes. Mol. Cell. Biol. 13: 7267-7277

14. Bondesson M, Mannervik M, Akusjarvi G and Svensson C (1994) An adenovirus E1A transcriptional repressor domain functions as an activator when tethered to a promoter. Nucleic Acids Res. 22: 3053-3060

15. Trouche D and Kouzarides T (1996) E2F1 and E1A12S have a homologous activation domain regulated by RB and CBP. Proc. Natl. Acad. Sci. USA 93: $1439-1442$

16. Wang HG, Moran E and Yaciuk P (1995) E1A promotes association between p300 and pRB in multimeric complexes required for normal biological activity. J. Virol. 69: 7917-7924

17. Lee CW, Sorensen TS, Shikama N and La Thangue NB (1998) Functional interplay between $\mathrm{p} 53$ and E2F through co-activator 300 . Oncogene 16: 2695 2710

18. Bannister AJ and Kouzarides T (1995) CBP-induced stimulation of c-Fos activity is abrogated by E1A. EMBO J. 14: 4758-4762

19. Ait-Si-Ali S, Ramirez S, Barre FX, Dikhissi F, Magnaghi-Jaulin L, Girault JA, Robin P, Knibiehler M, Pritchard LL, Ducommun B, Trouche D and Harel-Bellan A (1998) Histone acetyltransferase activity of CBP is controlled by cycledependent kinases and oncoprotein E1A. Nature 396: 184-186

20. Lowe SW and Ruley HE (1993) Stabilization of the p53 tumor suppressor is induced by adenovirus- $51 \mathrm{~A}$ and accompanies apoptosis. Genes Dev. 7:535545

21. Samuelson AV and Lowe SW (1997) Selective induction of p53 and chemosensitivity in RB-deficient cell by E1A mutants unable to bind RB-related proteins. Proc. Natl. Acad. Sci. USA 94: 12094-12099
22. Deng J, Xia W and Hung MC (1998) Adenovirus 5 E1A-mediated tumor suppressor associated with E1A-mediated apoptosis in vivo. Oncogene 17 $2167-2175$

23. Mymryk JS, Shire K and Bayley ST (1994) Induction of apoptosis by adenovirus type $5 \mathrm{E} 1 \mathrm{~A}$ in rat cells requires a proliferation block. Oncogene 9: 1187-1193

24. Querido E, Teodoro JG and Branton PE (1997) Accumulation of $p 53$ induced by the adenovirus $E 1 A$ protein requires regions involved in the stimulation of DNA synthesis. J. Virol. 71: 3526-3533

25. deStanchina E, McCurrach ME, Zindy F, Shieh SY, Ferbeyre G, Samuelson AV, Prives C, Roussel MF, Sherr CJ and Lowe SW (1998) E1A signaling to p53 involves the p19ARF tumor suppressor. Genes Dev. 12: 2434-2442

26. Bates S, Phillips AC, Clarke P, Scott F, Peters G, Ludwig RL and Vousden KH (1998) p14ARF links the tumor suppressors RB and p53. Nature 395: 124-125

27. Stott FJ, Bates S, James MC, McConnell BB, Starborg M, Brookes S, Palmero I, Ryan K, Hara E, Vousden KH and Peters G (1998) The alternative product from the human $C D K N 2 A$ locus, $\mathrm{p} 14^{\mathrm{ARF}}$, participates in a regulatory feedback loop with p53 and MDM2. EMBO J. 17: 5001-5014

28. Pomerantz J, Schreiber-Agus N, Liegeois NJ, Silverman A, Alland L, Chin L, Potes J, Chen K, Orlow I, Lee HW, Cordon-Cardo C and DePinho RA (1998) The INK4a tumor suppressor gene product, p19ARF, interacts with MDM2 and neutralizes MDM2's inhibition of p53. Cell 92: 713-723

29. Sanchez-Prieto R, Lleonart M and Ramon y Cajal S (1995) Lack of correlation between p53 protein level and sensitivity to DNA-damaging agents in keratinocytes carrying adenovirus E1A mutants. Oncogene 11: 675-682

30. Brader KR, Wolf JK, Hung MC, Yu D, Crispens MA, van Golen KL and Price JE (1997) Adenovirus E1A expression enhances the sensitivity of an ovarian cancer cell line to multiple cytotoxic agents through an apoptotic mechanism. Clin. Cancer Res. 3: 2017-2024

31. Teodoro JG, Shore GC and Branton PE (1995) Adenovirus E1A proteins induce apoptosis by both p53-dependent and p53-independent mechanisms. Oncogene 11: $467-474$

32. Marcellus RC, Teodoro JG, Wu T, Brough DE, Ketner G, Shore GC and Branton $P E$ (1996) Adenovirus type 5 early region 4 is responsible for E1A-induced p53independent apoptosis. J. Virol. 70: 6207-6215

33. Marcellus RC, Lavoie JN, Boivin D, Shore GC, Ketner G and Branton PE (1998) The early region 4 orf 4 protein of human adenovirus type 5 induces p53independent cell death by apoptosis. J. Virol. 72: 7144-7153

34. Boulakia CA, Chen G, Ng FW, Teodoro JG, Branton PE, Nicholson DW, Poirier GG and Shore GC (1996) Bcl-2 and adenovirus 19KDA protein prevent E1Ainduced processing of CPP32 and cleavage of poly(ADP-ribose) polymerase. Oncogene 12: 529-535

35. Lavoie JN, Nguyen M, Marcellus RC, Branton PE and Shore GC (1998) E4orf4, a novel adenovirus death factor that induces p53-independent apoptosis by a pathway that is not inhibited by zVAD-fmk. J. Cell Biol. 140: 637-645

36. Pützer BM, Bramson J, Addison CL, Hitt M, Siegel P, Muller WJ and Graham FL (1998) Combination therapy with Interleukin-2 and wild-type p53 expressed by adenoviral vectors potentiates tumor regression in a murine model of breast cancer. Hum. Gene Ther. 9: 707-718

37. Casciola RL, Nicholson DW, Chong T, Rowan KR, Thornberry NA, Miller DK and Rosen A (1996) Apopain/CPP32 cleaves protein that are essential for cellular repair: a fundamental principle of apoptotic death. J. Exp. Med. 183: 1957-1964

38. Chiou SK, Tseng CC, Rao L and White E (1994) Functional complementation of the adenovirus $\mathrm{E} 1 \mathrm{~B}$ 19-kilodalton protein with $\mathrm{Bcl}-2$ in the inhibition of apoptosis in infected cells. J. Virol. 68: 6553-6566

39. Kao CC, Yew PR and Berk AJ (1990) Domains required for in vitro association between the cellular p53 and the adenovirus 2 E1B 55K proteins. Virology 179 $806-814$

40. Wang HGH, Rikkitake Y, Corrigan Carter M, Yaciuk P, Abraham SE, Zerler B and Moran E (1993) Identification of specific adenovirus E1A N-terminal residues critical to the binding of cellular proteins and to the control of cell growth. J. Virol. 67: $476-488$

41. Barbeau D, Charbonneau R, Whalen SG, Bayley ST and Branton PE (1994) Functional interactions within adenovirus E1A protein complexes. Oncogene 9: $359-373$

42. Hsieh JK, Fredersdorf S, Kouzarides T, Martin K and Lu X (1997) E2F1-induced apoptosis requires DNA binding but not transactivation and is inhibited by the retinoblastoma protein through direct interaction. Genes Dev. 11: 1840-1852 
43. Shaw SB and Tegtmeyer $P$ (1981) Binding of dephosphorylated A protein to SV40 DNA. Virology 115: $88-96$

44. Lowe SW, Jacks T, Housman DE and Ruley HE (1994) Abrogation of oncogeneassociated apoptosis allows transformation of p53-deficient cells. Proc. Natl. Acad. Sci. USA 91: 2026-2030

45. Sabbatini P, Lin J, Levine AJ and White E (1995) Essential role for p53-mediated transcription in E1A-induced apoptosis. Genes Dev. 9: 2184-2192

46. Clarke AR, Purdie CA, Harrison DJ, Morris RG, Bird CC, Hooper ML and Wyllie AH (1993) Thymocyte apoptosis induced by p53-dependent and independent pathways. Nature 362: 849-852

47. Holmberg C, Helin K, Sehested M and Karlstrom O (1998) E2F-1-induced p53independent apoptosis in transgenic mice. Oncogene 17: 143-155

48. Donehower LA, Harvey M, Slagle BL, McArthur MJ, Mongomery CA, Butel JS and Bradley A (1992) Mice deficient of p53 are developmentally normal but susceptible to spontaneous tumours. Nature 356: $215-221$

49. Haas-Kogan DA, Kogan SC, Levi D, Dazin P, TÁng A, Fung YKT and Israel MA (1995) Inhibition of apoptosis by the retinoblastoma gene product. EMBO 14: 461-472

50. Chiou SK and White E (1997) p300 binding by E1A cosegregates with p53 induction but is dispensable for apoptosis. J. Virol. 71: $3515-3525$

51. Imperiale MJ, Kao HT, Feldman LT, Nevins J and Strickland S (1984) Common control of the heat shock gene and early adenovirus genes: evidence of cellular E1A-like activity. Mol. Cell. Biol. 4: 867-874

52. Fueyo J, Gomez-Manzano C, Yung WKA, Liu TJ, Alemany R, McDonnell TJ, Shi $X$, Rao JS, Levin VA and Kyritsis AP (1998) Overexpression of E2F-1 in glioma triggers apoptosis and suppresses tumor growth in vitro and in vivo. Nature Medicine 4: 685-690
53. Jelinek T, Pereira DS and Graham FL (1992) Tumorigenicity of adenovirustransformed rodent cells is influenced by at least two regions of adenovirus type 12 early region 1 A. J. Virol. $68: 888-896$

54. Stürzbecher HW, Brain R, Addison C, Rudge K, Remm M, Grimaldi M, Keenan E and Jenkins JR (1992) A c-terminal alpha-helix plus basic region motif is the major structural determinant of $p 53$ tetramerization. Oncogene 7: 1513-1523

55. Qin XQ, Chittenden T, Livingston DM and Kaelin WG (1992) Identification of a growth suppression domain within the retinoblastoma gene product. Genes Dev. 6: $953-964$

56. White E and Cipriani R (1990) Role of adenovirus E1B proteins in transformation: altered organization of intermediate filaments in transformed cells that express the 19-kilodalton protein. Mol. Cell. Biol. 10: 120-130

57. Van den Hoff MJB, Moorman AFM and Lamers WH (1992) Electroporation intracellular buffer increases cell survival. Nucleic Acids Res. 20: 2902.

58. Plumb JA, Milroy R and Kaye SB (1989) Effects of the pH dependence of 3-(4,5dimethylthiazol-2-yl)-2,5-diphenyl-tetrazolium bromide-formazan absorption on chemosensitivity determined by a novel tetrazolium-based assay. Cancer Res. 49: $4435-4440$

59. Gong J, Traganos F and Darzynkiewicz Z (1995) A selective procedure for DNA extraction from apoptotic cells applicable for gel electrophoresis and flow cytometry. Analytical Biochem. 218: 314-319

60. Kalejta RF, Shenk T and Beavis AJ (1997) Use of a membrane-localized green fluorescent protein allows simultaneous identification of transfected cells and cell cycle analysis by flow cytometry. Cytometry 29: 286-291 